IZA DP No. 6387

Run for Fun:

Intrinsic Motivation and Physical Performance

Antonio Filippin

Jan C. van Ours

February 2012 


\title{
Run for Fun: Intrinsic Motivation and Physical Performance
}

\author{
Antonio Filippin \\ University of Milan \\ and IZA \\ Jan C. van Ours \\ CentER, Tilburg University, \\ University of Melbourne, CEPR, CESifo and IZA
}

\section{Discussion Paper No. 6387 \\ February 2012}

\author{
IZA \\ P.O. Box 7240 \\ 53072 Bonn \\ Germany \\ Phone: +49-228-3894-0 \\ Fax: +49-228-3894-180 \\ E-mail: iza@iza.org
}

Any opinions expressed here are those of the author(s) and not those of IZA. Research published in this series may include views on policy, but the institute itself takes no institutional policy positions.

The Institute for the Study of Labor (IZA) in Bonn is a local and virtual international research center and a place of communication between science, politics and business. IZA is an independent nonprofit organization supported by Deutsche Post Foundation. The center is associated with the University of Bonn and offers a stimulating research environment through its international network, workshops and conferences, data service, project support, research visits and doctoral program. IZA engages in (i) original and internationally competitive research in all fields of labor economics, (ii) development of policy concepts, and (iii) dissemination of research results and concepts to the interested public.

IZA Discussion Papers often represent preliminary work and are circulated to encourage discussion. Citation of such a paper should account for its provisional character. A revised version may be available directly from the author. 
IZA Discussion Paper No. 6387

February 2012

\section{ABSTRACT \\ Run for Fun: \\ Intrinsic Motivation and Physical Performance*}

We use data from the 24-hours Belluno run which has the unique characteristic that participants are affiliated with teams and run for an hour. This allows us not only to study the individual relationship between age and performance but also to study group dynamics in terms of accessions to and separations from teams in a manner that closely resembles workers and firms when individual productivity would have been perfectly observable. From our analysis we conclude that individual performance goes down with age, although the speed-age gradient is rather flat. Group performance goes down with age as well, but interestingly a counterbalancing force emerges, namely team dynamics that are driven by performance of runners who enter and leave.

JEL Classification: J14, J24, J31

Keywords: age, performance, attrition

Corresponding author:

Antonio Filippin

University of Milan

Department of Economics and Business

via Consevatorio, 7

20122 Milan

Italy

E-mail: antonio.filippin@unimi.it

\footnotetext{
* The authors thank the organizers of the San Martino Marathon for making the data available, and Lorenzo Cappellari as well as participants to the XXXVI SAEe conference (Malaga) for helpful suggestions. The usual disclaimers apply.
} 


\section{Introduction}

Sports data have been used in economics for a wide range of purposes, from testing the incentive to sabotage in tournaments (del Corral et al. 2010) to analyzing the extent to which players conform to mixed strategy equilibria (Walker and Wooders, 2001). Sports data have also been exploited in order to gather a better understanding of human behavior. They have been extensively used to document the gender gap in competition both in childhood (Gneezy and Rustichini, 2004 and Sutter and Ruetzler, 2010) and in adulthood (Frick, 2011). Recently, some contributions have analyzed the role that pressure can exert on outcomes using data from professional soccer (Apesteguia and Palacios-Huerta, 2010) and hockey leagues (Kolev et al., 2011) as well as recruiting professional basket players (Feri et al., 2011).

Sports data can be important even for the analysis of relationships in labor economics that are hard to investigate using more traditional sources of data. Kahn (2000) claims that a sport is a very useful laboratory that can make much richer information available even than the Census. Similarly, Szymanski (2003) indicates that an analysis of sports data may be informative about labor market behavior of individuals. For instance, with sports data it is possible to investigate the relationship between age and productivity, which is a very interesting from a policy point of view because of aging populations (OECD, 2006). At the level of individual workers aging is assumed to have a negative effect on productivity but it is not clear from which age onward productivity starts to decline and it is not clear how strong the age effect is. Firms cope with the aging of their workforce through hirings and separations. Hiring may relate to young inexperienced workers who recently entered the labor market or may relate to more experienced workers who quit their job or come from the pool of unemployed. Separations may occur through layoffs or quits. In adjusting the workforce monetary incentives and other extrinsic motivations play an important role. For researchers it is difficult to study the relationship between age and performance related phenomena because it is usually not possible to measure productivity at the level of the individual worker. It is most often only at 
the level of the firm that productivity measures are available. Existing studies are inconclusive about the age-productivity gradient (see Van Ours and Stoeldraijer (2011) for details).

In our study we analyze running data. Previous studies using this type of sports data differ along an important dimension, because some concern performance of professional athletes while others study amateur athletes. Nevertheless, they all have in common that the measured performances are mostly or entirely driven by extrinsic rather than intrinsic motivations. The former comes from the external environment, out of the person, who acts with the anticipation of rewards, such as monetary prizes particularly salient in case of professional athletes, but also getting peer praise, or earning fans' admiration. Note that competition can be seen as extrinsic motivation as well, since the incentive to outperform the others comes from the external environment. On the contrary, intrinsic motivation occurs when the sport activity is enjoyable per se and a good performance constitutes a spur by itself, without other external incentives.

We study the relationship between age and running performance using a unique dataset, based on the 24-hour relay marathon "San Martino" held in Belluno (Italy) in which runners perform in teams. We use data from this marathon in the period 2002-2010. The data allow us to analyze individual and team performance and to study the process of selective attrition. The longitudinal data at individual level allow us to investigate the relationship between age and running performance taking into account unobserved personal characteristics. The fact that the runners are organized in teams with team performance as the relevant indicator makes our data truly unique. As explained in more detail below, runners run sequentially, which implies that the overall performance does not directly depend on the interaction between individuals since the team outcome is simply the sum of the individual outcomes. Moreover, there is no monetary incentive and the fact that every participant faces a (long) fixed amount of time rather than a fixed distance to run greatly weakens the role played by direct competition with the opponents. Our data allow us to study team dynamics in relation to individual 
running performance, since changes in the composition of running teams reflect how individual runners are recruited, quit or are dismissed.

Our contribution to the literature is twofold. First, our data allow us to measure individual level performance and to relate this to the age of runners, thereby adding to the small volume of papers which measure the age-productivity gradient using running data (see for example Fair (1994), Sterken (2003), Sowell and Mounts (2005) and Van Ours (2009)). Second, we investigate the turnover of runners between teams as well as other accessions and separations in a manner that we argue to be similar to worker and firm dynamics. Of course, the motivation of running teams are different from the motivation of actual firms. Nevertheless, as with real markets also in the Belluno marathon running teams enter and leave the arena and runners move from one team to the other or stop running while the team continues. For instance, our data allow us to analyze how new runners perform relatively to the average of their team, or whether runners experience upward or downward mobility. A distinguishing feature of our paper is that we study performance of individuals and teams who are almost entirely driven by intrinsic motivations.

The set-up of the paper is as follows. In section 2 we provide details about our data. Section 3 presents the results of our empirical analysis of the performance of individual runners. We find that age has a negative effect and we find that attrition is selective. Runners who perform bad in a run are less likely to participate in the next run. In section 4 we study team dynamics finding that team dynamics are very similar to "real world" hiring and separation phenomena. Section 5 concludes.

\section{The 24-hour marathon "San Martino"}

The 24 hour marathon "San Martino" is a relay race that involves a number of teams formed by 24 participants each running one hour. ${ }^{1}$ It takes place in Belluno (Italy) every year since 1974 in the athletics track of the municipal stadium. San Martino is the patron saint of Belluno, celebrated on the 11th

\footnotetext{
${ }^{1}$ More details (in Italian) at http://www.24oresanmartino.it/regolamento/SEZIO003/.
} 
of November. The relay race took place around that day in the first editions. Because of the usually unfavorable weather conditions in November, in the 1980s the race was moved to an earlier date and since then it takes place in the fist half of October.

The race always starts at 3 p.m. of Saturday and the changeovers take place at every hour. Relay runners have to be in a designated space a few minutes before their hour starts, where they wear a transponder that automatically measures the number of laps they run. The starting point is always at the finish zone of the 100mt. During the last 3 minutes of every hour each runner is given a baton that must be left on the ground at the exact point where the runner is when hearing the shot of the starter at the changeover. Any misbehavior (running after the shot, throwing the baton, etc.) is punished with the disqualification of the runner (the team is not disqualified but gets zero distance for that hour). The race is won by the team with the longest distance run by its 24 members (or less if someone does not participate), so that the team production function is simply given by the sum of the performances of the participants, which at least as first approximation excludes the existence of interaction effects among teammates that could affect the individual outcome.

The competition is open to males and females who are at least 16 years old. Every runner can participate only with one team and for one hour. Teams present a list of 24 runners ( +2 reserves). There are prizes for the best 5 teams, as well as for the best 20 male and 10 female runners, but the monetary value is very low. For instance, the best team receives a voucher worth $500 €$, the same amount paid by each team as a registration fee. Teams are enrolled on a first come first served basis with a limit of 40 teams in the last editions. Individual prizes also consist of vouchers, the value of which ranges from $40 €$ to $200 € .^{2}$ Individual rankings beyond the best 20 males and 10 females are not published. Results are published in local newspapers but on a hour by hour basis, so that it is almost impossible for a reader to reconstruct the whole ranking of the marathon. At the

\footnotetext{
${ }^{2}$ Data refer to the 2011 edition.
} 
same time, direct competition with the opponents in the same hour can be disregarded because after running for one hour it happens hardly ever that two runners end up close to each other. Similarly, the competition within a team should also not play a significant role. In fact, although the variance of results is lower within than across teams, it is not frequent that two teammates run a similar distance in such a way that the stimulus to outperform the first affects the performance of the second. Hence, both monetary and non monetary external rewards are negligible, and we can safely posit that the effort of the runners is (almost) entirely driven by intrinsic rather than extrinsic motivations.

Our dataset covers the last nine editions of the marathon. Table 1 shows that the size of the race increased in the period observed, with 10 more teams (i.e. about 240 more runners) in the last editions. Such an increase of participants has granted access to relatively slower runners, as shown by the steadily decreasing average performance. Such finding is not mirrored by the average individual distance of the best 3 teams that instead was rather stable. Statistics in Table 1 have been computed on the universe of participants $(\mathrm{N}=7446){ }^{3}$ The 7446 observations correspond to $\mathrm{n}=2896$ individuals, 367 of whom are female and will only be included in part of our empirical analysis. Unfortunately, the information about the year of birth has been collected only in four editions out of nine and is available for 1633 (male) runners. When missing, the information about age can be retrieved for the runners who also participate in some of the years in which it has been collected, i.e. for runners who participate more than once (2610 out of 3715 observations). This implies that information is not missing at random because the average performance is positively correlated with the number of participations. Not surprisingly, performance is significantly better for the runners for whom the age is available. However, in our empirical analysis we will always adopt fixed effect specifications, i.e. we analyze only the 1207 runners (4922 observations) with multiple participations, as summarized in

\footnotetext{
${ }^{3}$ This number is lower than the theoretical number $(\mathrm{N}=7464)$ for two reasons. First, 7 observations are really missing (runners disqualified or absent). Second, 11 observations have been deleted because the performance was more than $50 \%$ below the average in the other participations signalling an injury.
} 
Table 2. While still different in levels, the distribution of the performance in first differences is not significantly different between missing and non-missing observations of age (Mann-Withney test, Prob $>|z|=0.1885$ ).

Table 3 shows that although attrition is significant, many runners stay in the sample. For instance, of the 365 participants in 2002 (some of whom started even earlier) more than one third are still participating in 2010. The table also includes non-consecutive participations, and this explains why there are more runners in 2004 than in 2003 among those who participated in 2002. In fact, 42 runners participated in 2003 but not in 2004, while 51 participated in 2004 after having skipped the 2003 edition.

Performance is roughly normally distributed (see Figure 1) over a range between $10.3 \mathrm{~km}$ ( $1^{\text {st }}$ percentile) and $18.3 \mathrm{~km}$ ( $99^{\text {th }}$ percentile), showing a slightly negative correlation with age (Figure 2). There is a significant dispersion of the performance within teams, with runners that are going to dropout and (to a lower extent) new runners who display a relatively worse performance (Figure 3). As far as teams are concerned the picture is similar. Like for individuals, we consider only teams with multiple participations. ${ }^{4}$ Also in this case there is evidence of attrition (see Table 3), while the distribution of the performance is positively skewed (see Figure 4) over the range between $281 \mathrm{~km}$ ( $1^{\text {st }}$ percentile) and $416 \mathrm{~km}\left(99^{\text {th }}\right.$ percentile).

\section{Individual performance}

In our analysis of individual running performance we only include males. We consider only those who participate at least twice, so that we can introduce individual fixed effects. We start our analysis by relating the speed $y$ of participant $i$ in year $t$ to his age $a$, and to account for non-linearities we also include $a^{2}$ :

$$
\log \left(y_{i t}\right)=\alpha_{i}+\beta_{1} a_{i t}+\beta_{2} a_{i t}^{2}+\epsilon_{i t}
$$

\footnotetext{
${ }^{4}$ Moreover we drop the two observations referring to a team made only by new moms.
} 
where $\epsilon$ is an error term. The relevant parameter estimates are shown in Table $4 .^{5}$ Age has a significant nonlinear effect on running performance. Initially, age correlates positively with running speed, but after age 34 the performance starts to decline faster and faster. The speed-age gradient is $+0.15 \%$ at age $30,-0.17 \%$ at age $40,-0.49 \%$ at age 50 and $-0.81 \%$ at age 60 .

To check whether or not our data suffer from selective attrition we add participation in the next run as an additional explanatory variable, but we want to distinguish between a voluntary choice to quit from a possibly exogenous shock. For this reason, we define $S_{i, t+1}=1$ the event that the team stops, while we define $s_{i, t+1}=1 \mid S_{i, t+1}=0$ the event that the runner drops out once and for all voluntarily, i.e. when the team continues. A negative and significant coefficient of $s_{i, t+1}=1$ would be evidence of selective attrition (see Wooldridge (2002), page 581). The parameter estimates shown in Table 4 indicate that selective attrition is indeed a problem. Future dropout has a negative effect on the running speed in the current year, or in other words that fast runners are more likely to survive. Other things being equal, the $17 \%$ of observations that refer to individuals who stop running display an average speed that is lower, though only by $0.82 \%$. Also shown in Table 4 is the coefficient of $S_{i, t+1}=1$ that is not significantly different from zero. This is evidence supporting that team closure is an exogenous phenomenon at least from the point of view of the individual runner.

Our main conclusion is that age has a negative effect on running speed for runners in their mid thirties and older, with a drop in running speed that increases with age. Although the magnitude of the difference is not big, there is evidence of selective attrition and therefore the estimated drop in running speed due to age should be considered a lower bound.

Our results are consistent with the evidence in the literature. Fair (1994) studies U.S. data on men's running records finding that the age related physical deterioration is rather low. For example between age 35 and 55 the time needed to run the half marathon increases annually by $0.8 \%$, while between

\footnotetext{
${ }^{5}$ Note that in Table 4 the number of observations is lower than 4922 because we exclude 627 temporary interruptions as well as 557 observations that refer to 2010 and for which we cannot say anything about future participations.
} 
55 and 65 the annual increase is $1.1 \%$. This means for example that a runner aged 65 only needs $30 \%$ more time to run the half marathon than a runner aged 35 . In the age range 40 to 70 annual deterioration rates for sprint - 100, 200 and 400 meter track - are $0.6 \%$, for longer distances $0.8 \%$, for men 100 meter swimming $0.5 \%$. Although at higher ages the deterioration rates increase, for a fairly wide age range productivity losses are quite small. Sterken (2003) uses U.S. age-dependent road-racing records to analyze the relationship between age and running speed on various distances. He finds that even at a high age it is still possible to run fast, with a drop in speed in line with medical studies on the impact of aging on maximal oxygen uptake. Sowell and Mounts (2005) use data from the Ironman Triathlon World Championship to study the relationship between ability, age and performance. They find that although men achieve better than women in absolute sense, their relative performances are similar. A man age 65 is $44 \%$ slower than a man age 35, while for women the difference is $48 \%$. Van Ours (2009) analyzes the performance of participants in a Dutch 10 kilometers run (2009) finding that there is a negative effect of age on running speed from about age 40 onwards. He finds no evidence of selective attrition.

\section{Team performance and team dynamics}

\subsection{Team performance}

We start our empirical analysis of team performance using a similar set-up as before, now using team averages as dependent and explanatory variables:

$$
\log \left(\bar{y}_{j t}\right)=\alpha_{j}+\alpha_{t}+\beta_{3} \bar{a}_{j t}+\gamma \bar{w}_{j t}+\lambda e_{j t}+\varepsilon_{j t}
$$

where $\bar{y}_{j t}$ is the average speed of group $j$ in year $t, \bar{a}$ is average age, $\bar{w}$ represents the percentage of women in the group, $e$ is the team experience captured by the number of participations, $\alpha_{j}$ are team fixed effects and $\alpha_{t}$ 
are calendar time fixed effects. ${ }^{6}$ Finally, $\beta, \gamma$, and $\lambda$ are parameters and $\varepsilon$ is an error term. The parameter estimates are shown in Table 5 .

In the first estimate we find a significantly negative effect of the share of females in a team while team performance increases with experience. In the second estimate average age of the team is included, which has a negative effect on team performance. Including age does not change the effects of the share of females or team experience. In the third estimate a quadratic age term is introduced but this has a non-significant effect on running performance. Introducing a quadratic age term also removes the significance of the linear age term. Apparently the relationship between team performance and average age in linear. ${ }^{7}$

Returning to the first estimate, the footnote to Table 5 shows the parameter estimates for the calendar year fixed effects that capture the effect of time varying conditions, such as the weather, but that also represent changes in team composition that are not accounted for otherwise. A downward trend is apparent even though we control for the negative effect of the increasing average age. Although not significant, it suggests that additional investigation is needed to confirm that the increase in the size of the marathon allows relatively slower runners to be recruited. Notice that in spite of this downward trend teams manage to improve their performance by $0.8 \%$ a year, which is four time as much the decrease that should be observed due to the ageing of the participants. Intrinsic motivations alone, therefore, seem to be an effective device that drives team dynamics towards better performances, more than counterbalancing the age effect even in an environment in which slower and slower runners are recruited.

Finally, in the fourth estimate we investigate whether attrition at the team level is important but we find this not to be the case. The coefficient of

\footnotetext{
${ }^{6}$ Note that we can distinguish between average age and calendar year as well as between team experience and calendar year because of the group dynamics. If teams would always have the same runners we would not be able to do this as average age and calendar year would be perfectly correlated. The same would happen with team experience if all the teams participate in every edition. Note also that in equation (2) we assume that average age and team experience are exogenous to team performance.

${ }^{7}$ Note that it could be that we cannot distinguish a quadratic term from a linear one because the range over which average age varies is limited.
} 
$S_{i, t+1}$ is even positive although not significant, suggesting the possibility that faster teams are more likely to shut down. Although counterintuitive, this is observed from time to time in our dataset. In fact, teams that participate with some chances of winning the competition are sometimes characterized by a 'hit and run' strategy. For instance, a team with no more than 2 participations shows up in the first three positions 8 out of 27 times, most of which until 2005. The turnover among the top teams sharply decreases after 2005 , however, with the top positions systematically reached by teams with at least 5 participations. Overall, evidence in Table 5 confirms that teams are not characterized by selective attrition and therefore that a decision of a team to shut down is not driven by a poor performance of its runners.

\subsection{Team dynamics}

Teams greatly differ according to their degree of competitiveness, as shown by Figure 4, as well as in the number of participations. The majority of teams participate without chances of winning, and for this class of teams the objective function is either non measurable (conveying a message, soliciting charity, etc.) or totally unobservable (e.g. just fun). While at first glance this could cast a shadow on the importance of team dynamics in our dataset, we have shown in Table 5 that the incentive to improve the performance matters even though teams are driven by intrinsic motivations only. These results call for a more detailed analysis of the dynamic of inflows to and outflows from teams that we can do at the individual level thanks to the availability of individual records of productivity in our dataset.

\subsubsection{Outflow from teams}

We distinguish between two types of voluntary outflows from teams: quits and dropouts. In case of quits individual runners leave a team but they run again the next year for a different team. Dropouts are instead runners who stop running although their team continues. Both quits and dropouts are individual voluntary choices, as opposed to layoffs who are runners hit by 
the exogenous shock of their team shutting down. ${ }^{8}$

We model individual choices using linear probability models. The first two columns of Table 6 shows the parameter estimates. Quits are analyzed in levels (no fixed effects) because it's the level that matters, rather than the deviation from one's own average. The better the runner (in levels), the more likely he should be to experience upward mobility for instance because in the top teams more attention is paid to improving the aggregate performance. The dropouts are instead analyzed with fixed effects because in this case we conjecture that it is the variation with respect to a reference point like one's past performance that may trigger the decision. Our parameter estimates show that only the first of our conjectures is correct since faster runners are indeed more likely to change their team, while the difference with respect to one's average do not affect the likelihood of dropping out.

Comparing the performance with one's team-mates help to explain outflow decisions in both cases. Defining the relative performance as the percentage difference with respect to the average distance run by one's male team-mates, being better than the average decreases linearly the probability of dropping out. ${ }^{9}$

The relative performance displays a U-shaped effect on the likelihood of quitting, which is higher both for those worse than the average in $t-1$, i.e. those with a relative performance lower than zero, and for those better than the average. However, there are different patterns consistent with these results. For instance, a runner that decides to change team could be faster than his fellows in the new team either because he is really good, or because he left a good team to go in a worse one where he still performs better than the average. In other words, movers can experience both upward and downward mobility.

Table 7 analyzes upward and downward mobility, defined as the difference between the rank of the old team in $t-1$ minus the rank of the new

\footnotetext{
${ }^{8}$ Note that temporary interruptions are considered as dropouts in this section.

${ }^{9}$ Results are robust to including also females in the computation of the relative performance.
} 
team at time $t$, estimating the relation: ${ }^{10}$

$$
\Delta \operatorname{rank}_{i, t}=\alpha_{i}+\beta_{4} a_{i t}+\beta_{5} r e l_{i, t-1}+v_{i t}
$$

where $\operatorname{rel}_{i, t-1}$ is the percentage difference of the performance of runner $i$ as compared to the average of the old team and $v$ is an error term.

Results show a sizable effect of the relative performance of the runners in shaping their mobility, with a difference of $10 \%$ with respect to the average of the old team being associated with an improvment of 12.6 positions in the ladder with the new team. The bulk of the effect is due to the variance between runners better and worse than average as well as to the variance within those who are characterized by upward mobility. A similar correlation is not apparent within the movers worse than the average of their teams, as displayed in column 3. Age has no separate effect in this case.

Our results are robust to alternative specifications. In fact, we do not obtain very different insights once we include also the stayers in the analysis, assigning them the change in the rank of their own team from one year to another. This captures the idea that the strength of the same team can change in different editions, or in other words that teams as a whole can experience upward and downward mobility. The only difference is that a significantly positive correlation emerges even for the runners worse than the average, meaning that the worse the performance the bigger the decrease in the ladder.

Summarizing, the results in this section show that the decisions to leave a team are significantly correlated with the absolute and relative performance of the runners. The dynamics closely resemble what happens in the labor market. Runners dropping out parallel the situation in which workers decision to retire is affected by a lower relative productivity. Similarly, upward mobility of runners reminds the decision of the most productive workers to move when offered a higher wage by another firm. The striking feature of our results is that such dynamics are triggered by intrinsic motivations only.

\footnotetext{
${ }^{10}$ Note that a positive number stands for an improvement in the rank. The number of observations is low because we only consider consecutive participations of runners who voluntarily change their team.
} 


\subsubsection{Inflow to teams}

In this section we check whether productivity-driven dynamics are observed also as far as the inflow side is concerned. We can distinguish four types of entrants: 1) layoffs, i.e. those whose old team shut down, 2) quits, who are the same individuals as in the previous section but now we look at their destination, 3) runners returning after a temporary interruption, and 4) new entrants.

The third and fourth columns of Table 6 show parameter estimates for a linear probability model of the selection from the pool of unemployed. Clearly, better runners are more likely to find immediately a new team after the decision of the old team to shut down, confirming that also inflows are related to productivity.

The first column of Table 8 instead compares the average performance of the different types of runners with that of the stayers of their own team:

$$
\log \left(y_{i t}\right)=\alpha_{j}+\alpha_{t}+\alpha_{t y p e}+\beta_{6} a_{i t}+\beta_{7} a_{i t}^{2}+\beta_{8} e_{j t}+\omega_{i t},
$$

where $\alpha_{\text {type }}$ represent fixed effects for types of runners and $\omega$ is an error term. The regression controls for any observed and unobserved feature common to a team $\alpha_{j}$ or to a specific year $\alpha_{t}$ as well as for $e_{j t}$, the experience of team $j$ at time $t$. It shows that quits and laid-off runners are on average significantly better than the stayers, by $1.9 \%$ and $2.3 \%$, respectively. Returns do not

significantly differ, while new entrants are $2.3 \%$ slower. This result is in line with our expectations given the increase in the number of runners in recent years that made the entrance less and less selective. At the same time the average performance positively correlates with team experience, something that points towards the importance of the market for runners and that is analyzed in the next Section.

\subsubsection{Balance}

The first estimate of Table 5 shows that teams improve their performance by $0.7 \%$ a year. This is remarkable given that on the one hand the average 
performance decreases with time (see Table 1) and on the other hand that the average age increases by more than two years between 2002 and 2010. In fact, when controlling for the average age the annual improvement becomes $0.82 \%$. We also know that new runners display a performance below the average as shown in the first column of Table 8.

The nature of the inflow into and outflow from teams is what allows to reconcile these stylized facts. Team dynamics driven by productivity must therefore be strong enough to more than counterbalance the decreasing overall trend. In other words, the recruitment of new runners as well as the reallocation across teams of those who continue participating must be nonrandom in order to account for teams improving their performance.

The second column of Table 8 shows that indeed this is the case. This specification decomposes the effect of team experience interacting it with the type of runner. In other words, an interaction term between experience and type of runner is included. We already know that new runners are on average the slowest type. From descriptive statistics we can also see that, not surprisingly, new teams rely more heavily on this category. Moreover, now we also learn that new teams also hire worse new runners. In fact, results show that the average performance of new runners increases by $1.4 \%$ for every year of experience of the teams. This probably happens because experienced teams are more likely to be contacted by runners searching for a team, or more generally thanks to a better network of contacts. Similarly, teams become more and more capable of selecting among their pool of runners, given that also the average performance of the stayers significantly improves by $1.2 \%$ for every additional participation of a team. In contrast, incumbent teams do not seem capable of recruiting faster runners already in the market. While the point estimate is always positive coefficients are not significant, also because the number of observation in these cases is quite low.

All in all, we observe that teams exert effort clearly aimed at improving their performance. What we find particularly striking is that such dynamics are observed in the whole sample while only very few teams have some 
chances to compete to win the marathon. As long as runners can predict their individual performance with a reasonable precision, something that can safely be assumed, the great majority of the teams perfectly knows in advance that they have no chance of winning giving that the top teams have always displayed average performances above or about $18 \mathrm{~km} / \mathrm{h}$. Hence, the effort that teams successfully exert in the market for runners towards the improvement of the average performance is also driven by intrinsic motivations only.

\section{Conclusions}

Sports data can be informative about economic phenomena that are difficult to study with traditional economic data. We use data from the 24-hours Belluno run which has the unique characteristic that participants are affiliated with teams and run for an hour. This allows us not only to study the individual relationship between age and performance but also to study group dynamics in terms of accessions to and separations from teams in a manner that closely resembles workers and firms when individual productivity would have been perfectly observable. Another unique feature of our dataset is that direct financial incentives and more generally extrinsic motivations are to a large extent absent. Individual incentives and team allocation are almost entirely driven by intrinsic motivations.

From our analysis we conclude that individual performance goes down with age, although the speed-age gradient is rather flat. Moreover, runners are more likely stop racing if they under-perform relative to their team. Group performance goes down with age as well, but interestingly a counterbalancing force emerges, namely team dynamics driven by performance of runners who enter and leave. In a market economy firms try to deal with an aging workforce and keep their performance up-to-date by hirings and separations. Although there is no monetary incentive, running teams behave like if they are on a market in which productivity is the key variable. They have an incentive to stimulate group performance through reallocation of runners. These adjustments through accessions and separations are strong 
enough to more than counterbalance the age effect. We also find that the ability of teams to recruit relatively better new runners increases with their experience.

Although driven by intrinsic motivation, team dynamics are in line with a system of external monetary and non-monetary rewards. Runners who do well are more likely to quit for better teams. In case a team stops participating, runners who do well are more likely to immediately find another team. Similarly, runners that do worse than the average of their team are more likely to dropout the race. And, as in a real life labor market, age has a negative effect on the probability to quit and a positive effect on the probability to dropout.

All in all, our analysis shows that for individual runners as well as running teams incentives matter albeit through intrinsic motivation rather than through monetary stimuli or other extrinsic motivation. Individual runners behave as if they are workers in a firm. Teams behave as if they are firms which deal with an aging workforce and potential productivity decline through accessions and separations. 


\section{References}

- Apesteguia, J. and I. Palacios-Huerta (2010) Psychological pressure in competitive environments: evidence from a randomized natural experiment, American Economic Review, 100(5), 2548-64.

- Del Corral, J., J. Prieto-Rodrguez, and R. Simmons (2010) The effect of incentives on sabotage: the case of Spanish football, Journal of Sports Economics, 11, 243-260.

- Fair, R.C. (1994) How fast do old men slow down? Review of Economics and Statistics, 76, 103-118.

- Feri, G., A. Innocenti, and P.Pin (2011) Psychological pressure in competitive environments: Evidence from a randomized natural experiment: Comment, Working Papers in Economics and Statistics, Research Platform in Empirical and Experimental, University of Innsbruck, n. 2011-03.

- Frick B. (2011) Gender differences in competitive orientations: empirical evidence from ultra-marathon running, Journal of Sports Economics, 12(3), 317-340.

- Gneezy, U. and A. Rustichini (2004) Gender and competition at a young age, American Economic Review, 94(2), 377-381.

- Kahn, L.M. (2000) The sports business as a labor market laboratory, Journal of Economic Perspectives, 14, 75-94.

- Kolev, G.I., G. Pina, and F. Todeschini (2010) Overconfidence in competitive environments: evidence from a quasi-natural experiment, mimeo.

- OECD (2006) Live longer, work longer, Paris.

- Sowell, C.B. and W.S. Mounts (2005) Ability, age, and performance, Journal of Sports Economics, 6, 78-97.

- Sterken, E. (2003) From the cradle to the grave: how fast can we run? Journal of Sports Science, 21, 479-491.

- Sutter, M. and D. Ruetzler (2010) Gender differences in competition emerge early in life, IZA DP No. 5015.

- Szymanski, S. (2003) The assessment: the economics of sport, Oxford Review of Economic Policy, 19, 467-477.

- Van Ours, J.C. (2009) Will you still need me when I'm 64? De Economist, 157, 441-460.

- Van Ours, J.C. and L. Stoeldraijer (2011) Age, wage and productivity in Dutch manufacturing, De Economist, 159, 113-137.

- Walker, M. and J. Wooders (2001) Minimax play at Wimbledon, American Economic Review, 91(5), 1521-1538.

- Wooldridge, J.M. (2002) Econometric Analysis of Cross Section and Panel Data, Cambridge, MIT Press. 
Table 1: Descriptive statistics

\begin{tabular}{l|cccccc}
\hline Edition & N.of teams & Age & $\begin{array}{c}\text { Fraction } \\
\text { of females }\end{array}$ & $\begin{array}{c}\text { Distance } \\
\text { (average) }\end{array}$ & $\begin{array}{c}\text { Distance } \\
\text { (males) }\end{array}$ & $\begin{array}{c}\text { Distance } \\
\text { (best 3 teams) }\end{array}$ \\
\hline 2002 & 29 & 36.9 & $8.5 \%$ & 14408.1 & 14570.1 & 17017.7 \\
2003 & 29 & 37.7 & $7.5 \%$ & 14414.1 & 14581.3 & 16545.7 \\
2004 & 32 & 38.6 & $9.8 \%$ & 14016.3 & 14222.6 & 16005.4 \\
2005 & 32 & 38.2 & $10.8 \%$ & 14141.3 & 14380.3 & 16550.8 \\
2006 & 36 & 38.6 & $9.5 \%$ & 14042.6 & 14232.1 & 16303.8 \\
2007 & 34 & 38.7 & $9.2 \%$ & 14094.2 & 14276.0 & 16559.2 \\
2008 & 39 & 39.5 & $10.1 \%$ & 14066.1 & 14266.6 & 17240.8 \\
2009 & 39 & 39.8 & $12.1 \%$ & 13874.7 & 14132.4 & 17332.1 \\
2010 & 39 & 39.2 & $12.8 \%$ & 13790.5 & 14046.8 & 16269.6 \\
\hline
\end{tabular}

Note: Distance in meters, all participants. Two teams (one in 2007 another in 2008 dropped because $100 \%$ female)

Table 2: Missing data

\begin{tabular}{l|cc}
\hline & Individuals (n) & Observations (N) \\
\hline Female & 367 & 800 \\
Only one participation & 1096 & 1096 \\
Age missing, not inputed & 226 & 628 \\
Age non missing & 1207 & 4922 \\
(of which inputed) & & $(2608)$ \\
\hline Total & 2896 & 7446 \\
\hline & Age missing & Age non missing \\
\hline Distance (level) & 14201.1 & 14408.1 \\
Distance (1 ${ }^{\text {st }}$ diff) & -20.0 & -2.2 \\
Nr of participations & 3.5 & 5.0 \\
Age & $\cdot$ & 39.0 \\
\hline
\end{tabular}


Table 3: Attrition; individual runners and teams

\begin{tabular}{l|ccccccccc|c}
\hline Started & \multicolumn{2}{|c}{ Participated in } & & & & & & \\
in & 2002 & 2003 & 2004 & 2005 & 2006 & 2007 & 2008 & 2009 & 2010 & Total \\
\hline \multicolumn{2}{l}{ a. Individual runners } & & & & & & & & \\
\hline$\leq 2002$ & 365 & 275 & 284 & 234 & 218 & 184 & 171 & 158 & 137 & 2026 \\
2003 & & 169 & 135 & 108 & 89 & 70 & 60 & 46 & 39 & 716 \\
2004 & & & 150 & 105 & 98 & 73 & 65 & 60 & 50 & 601 \\
2005 & & & & 122 & 96 & 73 & 60 & 48 & 43 & 442 \\
2006 & & & & & 111 & 94 & 64 & 51 & 60 & 380 \\
2007 & & & & & & 124 & 101 & 82 & 62 & 370 \\
2008 & & & & & & & 75 & 54 & 74 & 203 \\
2009 & & & & & & & & 92 & 92 & 184 \\
\hline Total & 365 & 444 & 569 & 569 & 612 & 619 & 596 & 591 & 557 & 4922 \\
\hline b. Teams & & & & & & & & & \\
\hline$\leq 2002$ & 25 & 25 & 22 & 19 & 19 & 15 & 15 & 13 & 13 & 166 \\
2003 & & 3 & 3 & 3 & 3 & 2 & 2 & 1 & 0 & 17 \\
2004 & & & 5 & 5 & 3 & 3 & 3 & 3 & 3 & 25 \\
2005 & & & & 5 & 5 & 5 & 4 & 3 & 3 & 25 \\
2006 & & & & & 6 & 6 & 5 & 4 & 4 & 25 \\
2007 & & & & & & 3 & 3 & 3 & 2 & 11 \\
2008 & & & & & & & 5 & 5 & 4 & 14 \\
2009 & & & & & & & & 6 & 6 & 12 \\
\hline Total & 25 & 28 & 30 & 32 & 36 & 34 & 37 & 38 & 35 & 295 \\
\hline
\end{tabular}

Note: panel $a$ of the table includes temporary interruptions. This explains for instance why there are more runners in 2004 than in 2003 among those who started in 2002 . In fact 42 runners participated in 2003 but not in 2004, while 51 participated in 2004 after having skipped the 2003 edition. Panel $b$ of the table include teams with at least two participations, also considering temporary interruptions. 
Table 4: Speed and age: Individual (log) distance

\begin{tabular}{c|cccc}
\hline & age & age $^{2}$ & $s_{t+1}$ & $S_{t+1}$ \\
\hline 1. & $1.09(4.6)^{* *}$ & $-0.016(5.7)^{* *}$ & - & - \\
2. & $1.15(4.8)^{* *}$ & $-0.016(5.7)^{* *}$ & $-0.82(3.0)^{* *}$ & - \\
3. & $1.15(4.8)^{* *}$ & $-0.016(5.7)^{* *}$ & $-0.84(3.1)^{* *}$ & $-0.20(0.8)$ \\
\hline
\end{tabular}

Note: the estimates are based on 3738 observations of 1160 individuals; individual fixed effects are included; robust standard errors; the age effects reflect percentage change by year of age; absolute $t$-statistics in parentheses; $* *(*)=$ significant at $5 \%(10 \%)$ level.

Table 5: Age, experience and speed: Group (log) distance

\begin{tabular}{c|ccccc}
\hline & \% female & experience & age & age $^{2}$ & $S_{t+1}$ \\
\hline 1. & $-0.21(7.2)^{* *}$ & $0.71(1.8)^{*}$ & - & - & - \\
2. & $-0.20(7.2)^{* *}$ & $0.82(2.1)^{* *}$ & $-0.23(2.6)^{* *}$ & - & - \\
3. & $-0.20(7.3)^{* *}$ & $0.88(2.2)^{* *}$ & $0.75(0.8)$ & $-1.28(1.0)$ & - \\
4. & $-0.20(7.2)^{* *}$ & $0.75(1.8)^{*}$ & $-0.22(2.5)^{* *}$ & - & $0.46(0.7)$ \\
\hline
\end{tabular}

Note: the estimates are based on 295 observations of 58 teams; group fixed effects and calendar year fixed effects are included; in the second specification the calendar year fixed effects where as follows (2002 = base year): 20030.01 (0.0); 2004 -1.79 (1.8)*; 2005 -1.59 (1.2); 2006 -2.24 (1.4); 2007 -2.30 (1.2); 2008 -2.94 (1.3); 2009 -3.38 (1.3); 2010 -2.51 (0.8). All the coefficients represent percentage changes; absolute $t$-statistics in parentheses; $*^{*}(*)=$ significant at $5 \%(10 \%)$ level. 
Table 6: Probability of quitting, dropping out and finding a new team when laid off

\begin{tabular}{l|cccc}
\hline & Quit & Dropout & Inflow from unemployment \\
\hline Distance (log) & $.135(2.4)^{* *}$ & $.016(0.6)$ & $0.396(1.5)$ & $0.692(3.7)^{* *}$ \\
Relative perf. & $-.007(0.9)$ & $-.062(3.5)^{* *}$ & $0.059(1.8)^{*}$ & - \\
Relative perf. & $0.102(2.2)^{* *}$ & - & - & - \\
Age & $-0.082(1.9)^{*}$ & $3.53(9.2)^{* *}$ & $-0.18(0.7)$ & $-0.18(0.8)$ \\
Fixed effects & no & yes & no & no \\
\hline $\mathrm{R}^{2}$ & .005 & .001 & 0.04 & 0.03 \\
$\mathrm{~N}$ & 4365 & 4365 & 497 & 497 \\
$\mathrm{n}$ & & 1209 & & \\
\hline
\end{tabular}

Note: Robust standard errors; coefficients reflect percentage change by year of age and by $10 \%$ of relative performance; absolute $t$-statistics in parentheses; $*^{*}(*)=$ significant at $5 \%(10 \%)$ level.

Table 7: Upward and downward mobility

\begin{tabular}{l|ccc}
\hline & \multicolumn{3}{|c}{ Dependent variable: difference in the rank } \\
& All & Above average & Below average \\
\hline Relative performance & $12.6(5.8)^{* *}$ & $9.6(3.7)^{* *}$ & $-13.4(1.2)$ \\
Age & $.02(0.0)$ & $-.43(0.3)$ & $2.6(1.5)$ \\
Fixed effects & yes & yes & yes \\
\hline $\mathrm{R}^{2}$ & .26 & .16 & .001 \\
$\mathrm{~N}$ & 313 & 171 & 142 \\
\hline
\end{tabular}

Note: Robust standard errors; coefficients reflect change in the rank by $10 \%$ of relative performance; absolute $t$-statistics in parentheses; ${ }^{* *}\left({ }^{*}\right)=$ significant at $5 \%(10 \%)$ level. 
Table 8: Team dynamics and balance

\begin{tabular}{l|c|c}
\hline Dep var: $\log$ (distance) & $(1)$ & $(2)$ \\
\hline new & $-2.3(5.4)^{* *}$ & $-2.7(3.8)^{* *}$ \\
layoff & $2.2(2.1)^{* *}$ & $4.8(2.8)^{* *}$ \\
quit & $1.9(2.3)^{* *}$ & $3.8(2.9)^{* *}$ \\
return & $.45(1.0)$ & $1.2(1.2)$ \\
experience & $1.2(2.1)^{* *}$ & - \\
stayer*experience & - & $1.2(2.4)^{* *}$ \\
new*experience & - & $1.4(2.5)^{* *}$ \\
layoff*experience & - & $0.5(0.7)$ \\
quit*experience & - & $0.7(1.0)$ \\
return*experience & - & $1.1(2.0)^{*}$ \\
age & $.42(2.8)^{* *}$ & $.43(2.9)^{* *}$ \\
age & $-.008(4.5)^{* *}$ & $-.008(4.6)^{* *}$ \\
team fixed effects & yes & yes \\
year fixed effects & yes & yes \\
\hline $\mathrm{R}^{2}$ & .11 & .11 \\
$\mathrm{~N}$ & 4434 & 4434 \\
\hline \hline
\end{tabular}

Note:

N.B. We consider only teams with multiple and consecutive participations and runners with multiple participations. Omitted type: stayer. Robust standard errors; coefficients reflect percentage changes; absolute $t$-statistics in parentheses; $* *(*)=$ significant at $5 \%(10 \%)$ level. 
Figure 1: Frequency distribution of distance per runner

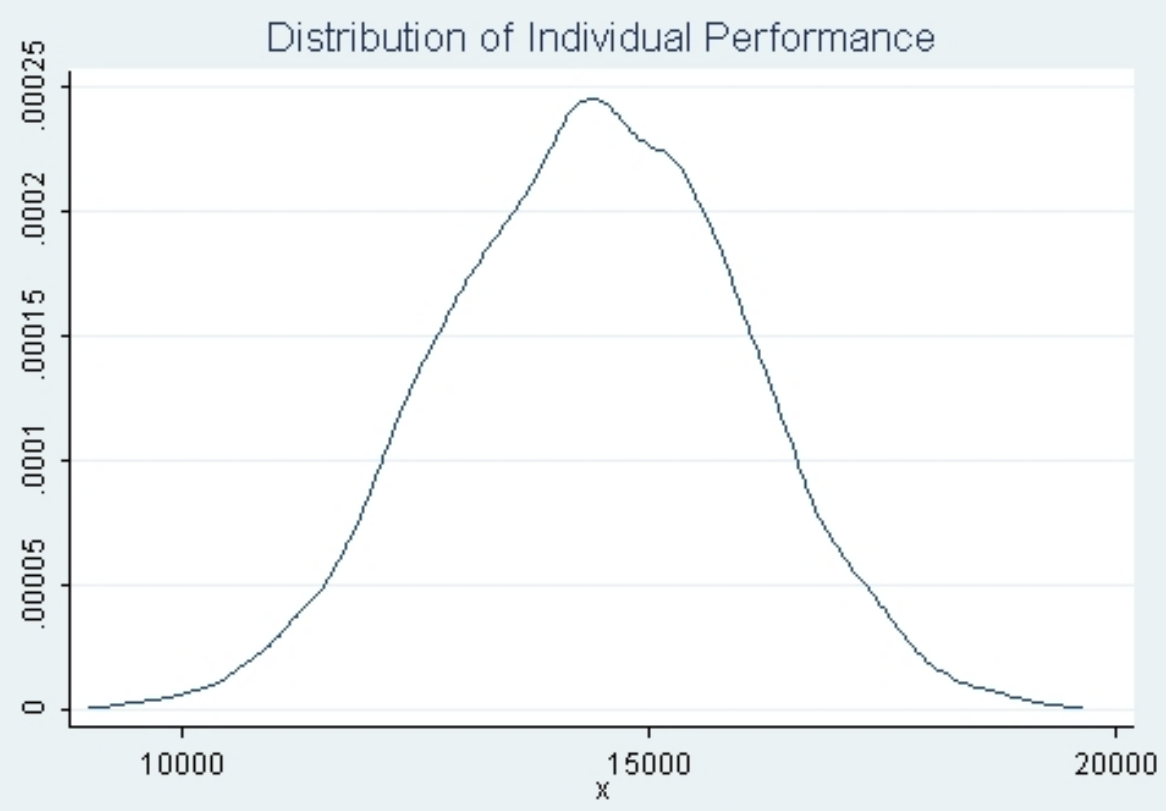

Figure 2: Boxplot of performance by age

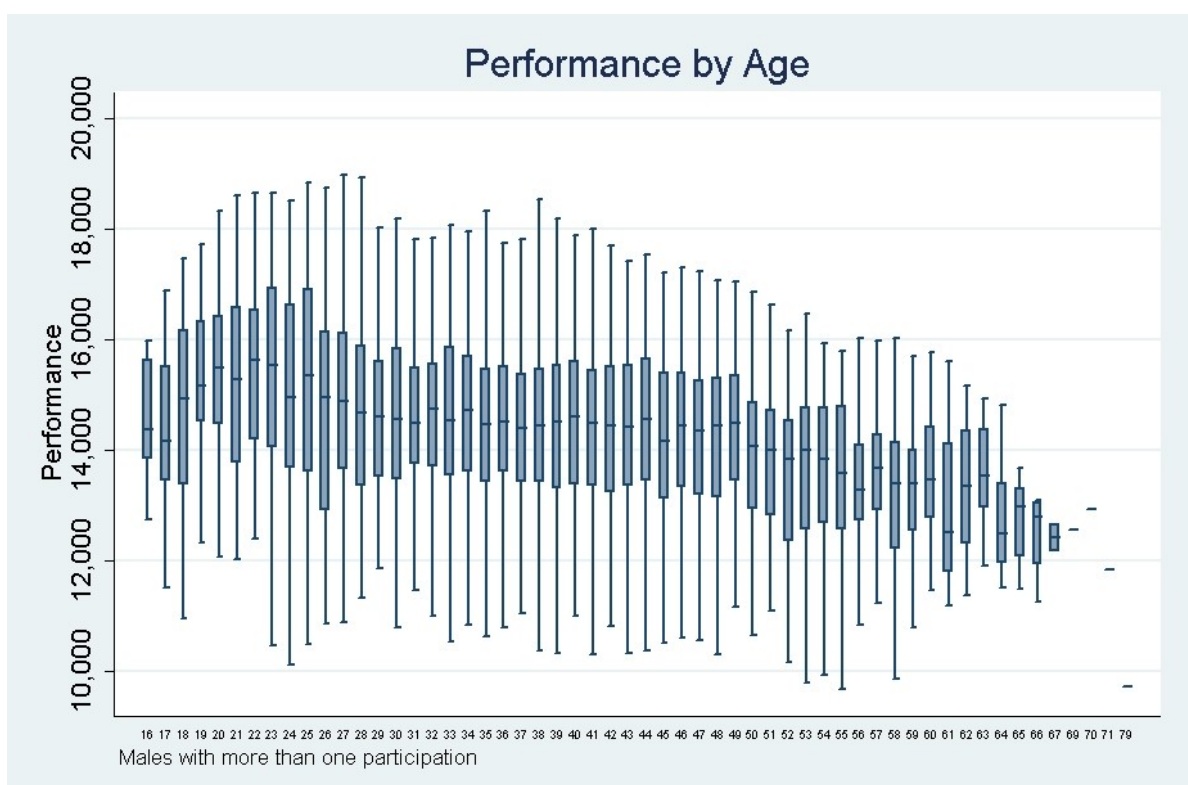


Figure 3: Frequency distribution of distance relative to one's team

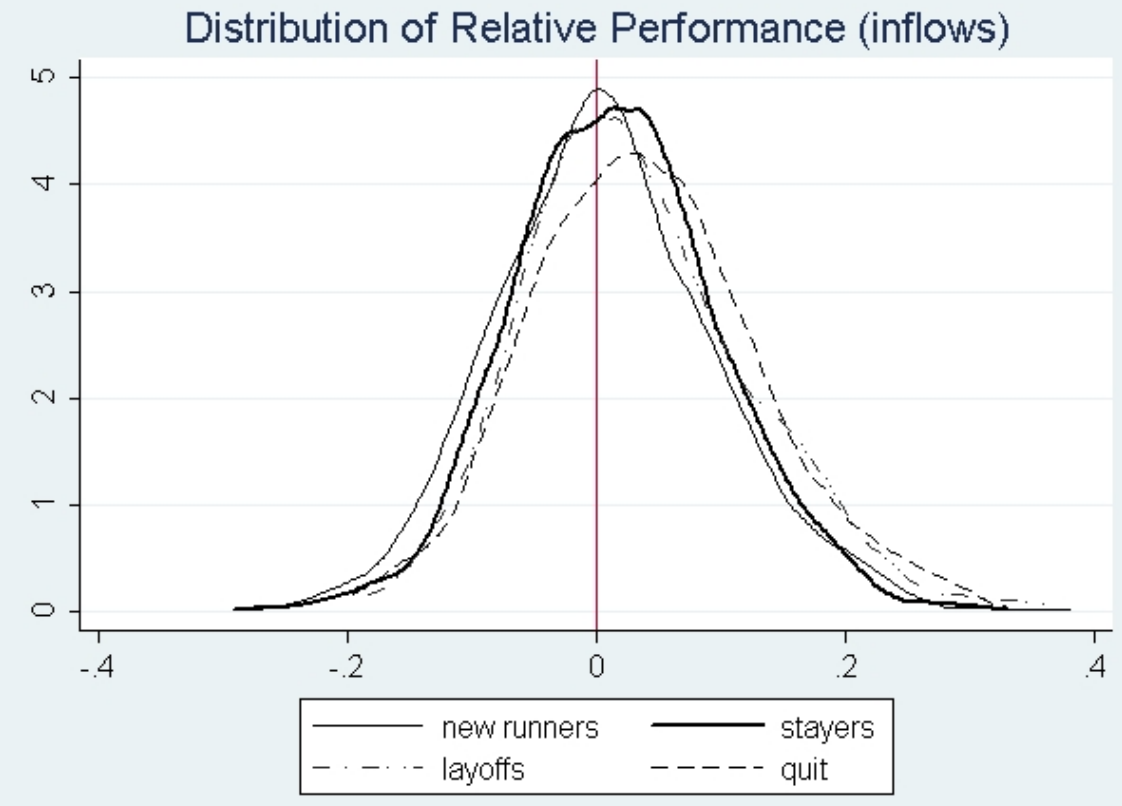

Figure 4: Frequency distribution of distance per team

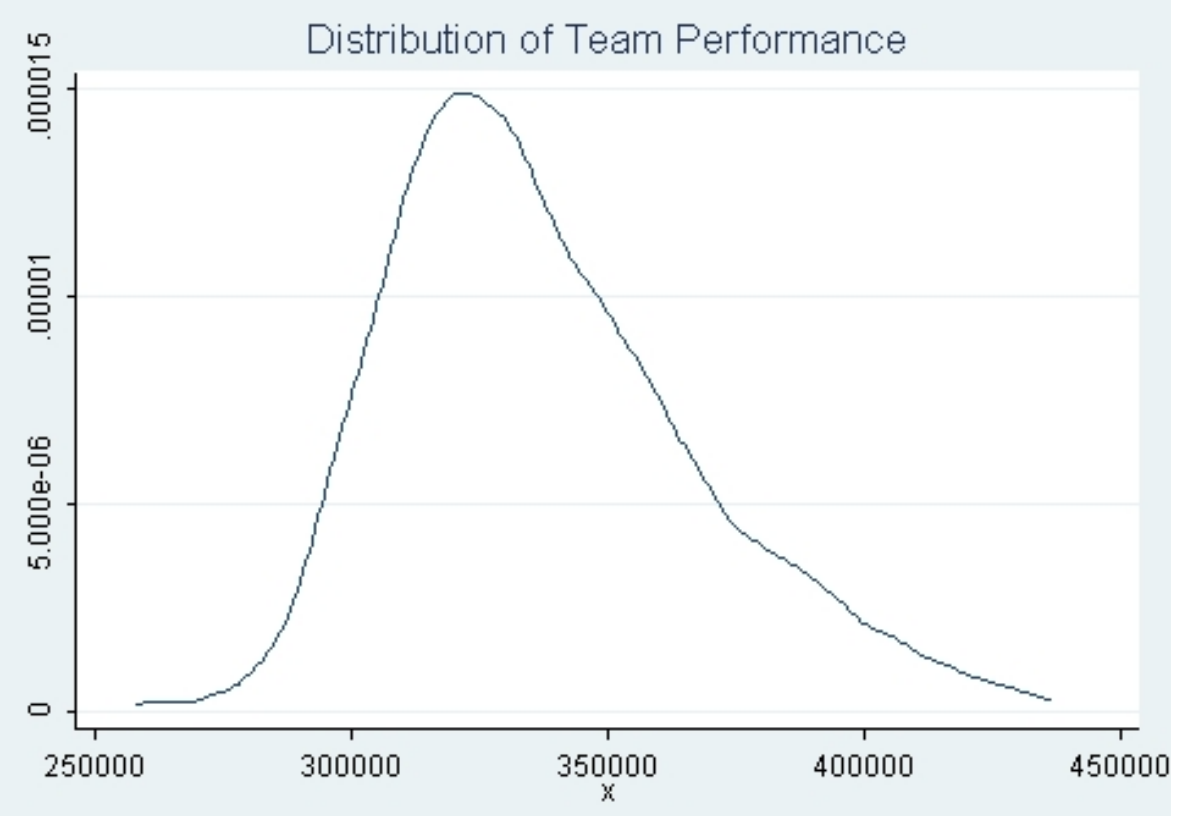

